\title{
Nivolumab-induced severe bullous pemphigoid in a patient with renal cancer: a case report and literature review
}

\author{
Xiaorong Wu, Sreekanth Palvai, Awais Jalil \\ Department of Medical Oncology, Southend University Hospital NHS Foundation Trust, Prittlewell Chase, Westcliff-on-Sea, \\ Essex SSO ORY, United Kingdom.
}

Correspondence to: Dr. Xiaorong Wu, Department of Medical Oncology, Southend University Hospital NHS Foundation Trust, Prittlewell Chase, Westcliff-on-Sea, Essex SSO ORY, United Kingdom. E-mail: Xiaorong.wu@nhs.net

How to cite this article: Wu X, Palvai S, Jalil A. Nivolumab-induced severe bullous pemphigoid in a patient with renal cancer: a case report and literature review. J Cancer Metastasis Treat2020;6:40. http://dx.doi.org/10.20517/2394-4722.2020.77

Received: 30 Jul 2020 Accepted: 23 Oct 2020 Published: 29 Oct 2020

Academic Editor: Godefridus J. Peters Copy Editor: Cai-Hong Wang Production Editor: Jing Yu

\begin{abstract}
With the widespread use of immunotherapy in numerous solid tumours, immunotherapy-related adverse events (irAEs) have started to emerge and bring new challenges for clinicians to manage. Among established irAEs, dermatologic toxicity is one of the most common toxicities; it is often mild but can be severe and potentially life-threatening, such as bullous pemphigoid. Here, we report a case of nivolumab-mediated severe, extensive, refractory bullous pemphigoid involving both skin and oral mucosa in a patient with metastatic renal cancer. We also summarise a list of selected case reports of immunotherapy-induced bullous pemphigoid by literature review. We highlight various presentations, investigations and managements of this type of skin irAEs. Meantime, we would like to discuss the correlation of skin irAEs incidence rate with immunotherapy drug benefit and resistance.
\end{abstract}

Keywords: Bullous pemphigoid, mucous membrane pemphigoid, immunotherapy, dermatologic toxicity, nivolumab

\section{INTRODUCTION}

Immunotherapy, such as anti-programmeddeath-1 (PD-1)/programmed death ligand 1 (PD-L1) antibody or anti-CTLA 4 antibody or combination, has significantly improved survival of patients with various malignancies. However, immunotherapy-related adverse events (irAEs) have started to emerge and bring new challenges for oncologists to manage. Among the known irAEs, dermatologic toxicity is one of the

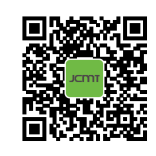


most common toxicities ${ }^{[1]}$. Most immunotherapy-induced cutaneous toxicities are mild, such as nonspecific rashes or pruritus. However, some manifestations of skin irAEs can progress to high-grade and potentially life-threatening situations, such as bullous pemphigoid $(B P)^{[2]}$. Since 2015 , more than 40 cases of immunotherapy-induced BP have been reported with the majority involving either the skin or mucous membrane only. Presentations of both cutaneous and oral mucous BP are rare (less than seven cases).

Here, we report a severe, extensive (involving both skin and oral mucosa), refractory case of BP that occurred 9 months after initiation of nivolumab in a patient with metastatic renal clear cell cancer. We also summarise a list of selected case reports of checkpoint inhibitor-induced BP by literature review. We highlight various presentations, investigations and management approaches of immunotherapy-induced BP. Meantime, we would like to discuss the correlation of skin irAE incidence rate with immunotherapy drug benefit and resistance.

\section{CASE REPORT}

A 66-year-old gentleman with no known history of autoimmune disease was diagnosed with right clear renal cancer in 2014. He was initially treated with radical nephrectomy with excision of tumour thrombus in the renal vein and retro-hepatic inferior vena cava. In March 2017, his cancer relapsed with a single spinal metastasis, which was treated with excision of the intradural tumour and laminectomy and radiotherapy as well, which resulted in complete neurological recovery. Post-radiotherapy, he opted for active tyrosine kinase inhibitor, sunitinib, in light of relapsed renal cancer in his spine. In October 2017, sunitinib was discontinued due to spontaneous haematoma in his right calf and thigh, which was likely due to combination of sunitinib and low-molecular-weight heparin (LMWH) for his atrial fibrillation. He then had a long period of surveillance, during which he gradually developed asymptomatic relapsed metastatic renal cancer in his left adrenal gland, followed by relapsed cancer in his left kidney. In March 2019, he commenced immunotherapy infusion with 2 weekly nivolumab, considering further disease progression with multiple lung metastatic disease. His other medical history was only atrial fibrillation, for which he was on LMWH and bisoprolol.

From August 2019, five months post-initiation of nivolumab, he developed a mild pruritic erythematous skin rash scattered mainly over his chest and upper limbs. At that time, there were no blisters reported. He continued nivolumab with the rash controlled mainly by topical steroids or short courses of oral steroids. In November 2019, he developed large, tense, haemorrhagic blisters, which were exacerbated following a 3-week holiday in Australia, leading to an emergency hospital admission. On clinical examination, he had a severe widespread bullous eruption affecting his chest, abdomen, inner thighs and upper arms. Active blisters and erosions were seen on the roof of his mouth and scrotal skin as well. Some blisters had burst leaving severely eroded skin with signs of superimposed infection. Bullae at various stages were seen, including intact ones, burst ones with an eroded base, and a few areas of early re-epithelialisation as Figure 1. He had no involvement of the scalp region and external eye examination was normal.

An incisional skin biopsy from an active blister with haematoxylin and eosin examination revealed epidermal hyperplasia and subepidermal splitting. There were few eosinophils, scattered plasma cells and neutrophils with a subjacent chronic inflammation. Direct immunofluorescence (DIF) showed clearly positive staining for IgG in the basement membrane zone, and a faint positive IgA staining. Subsequent serum antibody analysis confirmed positive pemphigoid antibodies consistent with BP see Figures 2 and 3.

The patient was started immediately on intravenous methylprednisolone $1 \mathrm{mg} / \mathrm{kg}$ as well as flucloxacillin for 4 days and then switched to oral prednisolone and flucloxacillin when no new blisters developed. Most of the blisters gradually re-epithelialised within 4-6 weeks of oral steroids. Two months later, the corticosteroid treatment was tapered. However, the blisters reappeared when prednisolone was stepped 

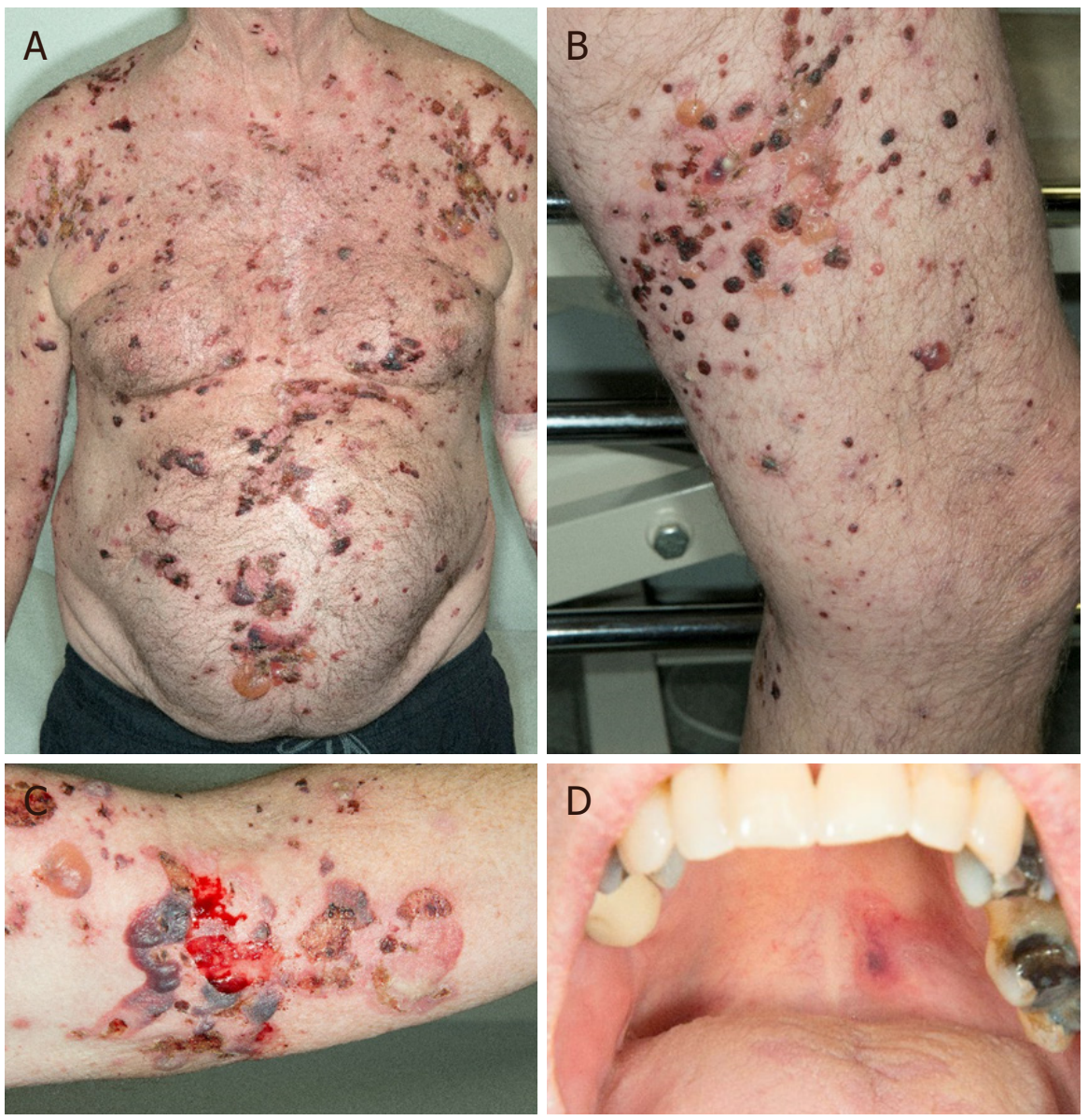

Figure 1. Clinical presentations. Multiple, grouped, large, tense haemorrhagic blisters were seen on the first clinical presentation, which affected the chest, abdomen, inner thighs and upper arms (A, B and C); active blisters and erosions were seen on the roof of the mouth (D)
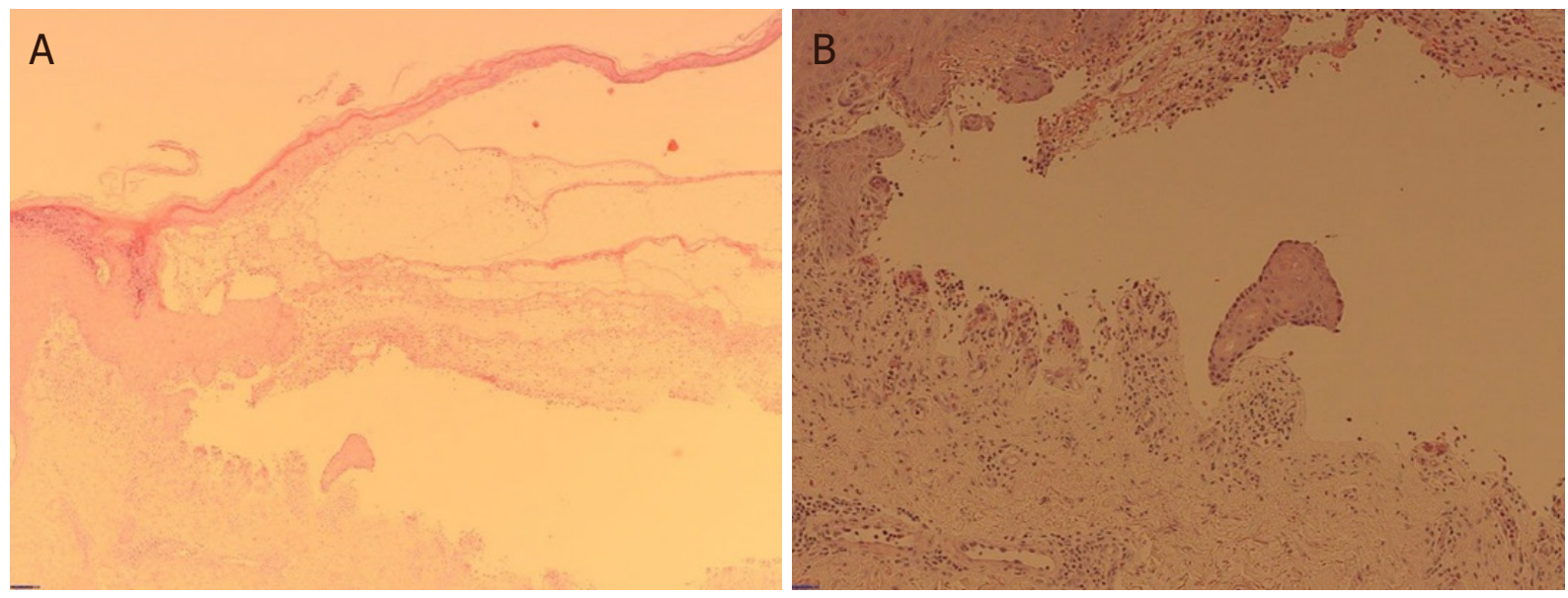

Figure 2. Haematoxylin and eosin staining of edge (A) and base (B) of blisters. Epidermal hyperplasia and subepidermal splitting were seen with few eosinophils, scattered plasma cells, neutrophils and a subjacent chronic inflammation

down to $10 \mathrm{mg}$ per day, requiring re-introduction of high-dose prednisolone. Consequently, nivolumab had been permanently discontinued in view of refractory BP and further disease progression in his adrenal metastatic disease. 

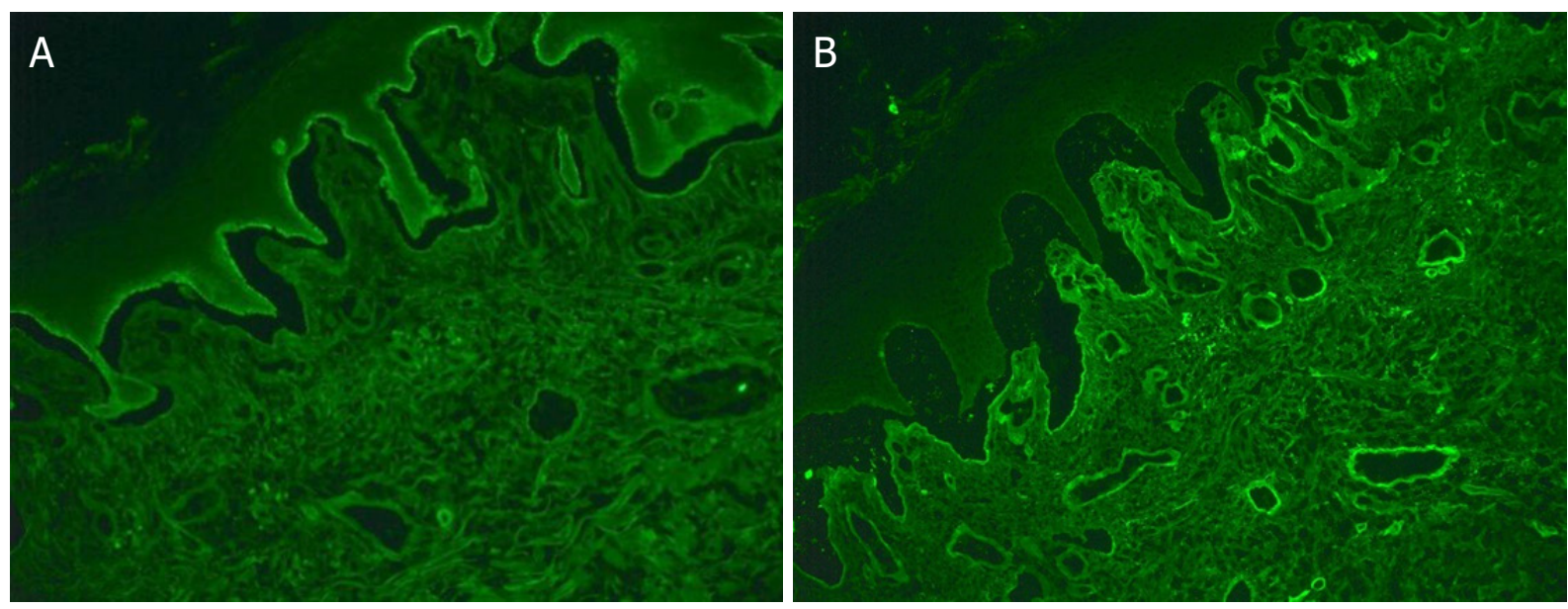

Figure 3. Direct immunofluorescence showed clearly positive staining for lgG in the basement membrane zone (A), and a faint positive $\lg$ A staining (B)

\section{DISCUSSION}

$\mathrm{BP}$ is an autoimmune blistering disorder that is caused by autoantibodies against hemidesmosomal protein BP180 and BP230 at the skin basement membrane ${ }^{[1]}$. The causes of BP in oncologic patients could be idiopathic, paraneoplastic ${ }^{[2,3]}$, secondary to cancer therapy or related to another medication. With the widespread use of immunotherapy in cancer management, BP has become a well-established cutaneous toxicity associated with immunotherapy. The cause of BP in our case is most likely nivolumab, as the patient denied a history of BP, and as his other medications were generally tolerated for years. The timing of his renal cancer diagnosis ( 5 years prior) and nivolumab initiation ( 9 months prior) makes the paraneoplastic phenomenon highly unlikely.

Here, we summarise a list of selected case reports of immunotherapy induced BP by literature review in Table 1. Most reported immunotherapy-induced BP involving either skin or mucous membrane only Table 1; combination of cutaneous BP and mucous membrane pemphigoid (MMP) is rare ${ }^{[4]}$. Cutaneous BP typically presents with pruritic blisters that arise on erythematous or urticarial plaques. Gradually, the bullous lesion can erode and leave haemorrhagic crust ${ }^{[5]}$. MMP usually presents with oral erosions, blistering or desquamative gingivitis, which are associated with significant morbidity and severe complications, such as tissue destruction, fibrosis and loss of function (e.g., laryngeal stenosis). In addition, MMP could be initially indistinguishable from a gingivitis due to poor oral hygiene practices ${ }^{[6]}$. Thus, oncologists should be aware of cutaneous BP and MMP in all patients who have been treated with immunotherapy.

Onset of BP post-initiation of immunotherapy varies from weeks to several months [Table 1]. Previous evidence showed that the median number of weeks of immunotherapy prior to onset of BP was 17 (range of 3 to 91$)^{[7]}$. However, delayed cases have been reported, even several months after discontinuation of immunotherapy ${ }^{[8,9]}$.

Diagnostic workup usually includes skin biopsy for histology and immunofluorescence staining. Histopathology normally shows subepidermal clefting with an eosinophilic inflammatory infiltration ${ }^{[10]}$. DIF characteristically shows linear deposits of IgG and/or C3 along the epidermal basement membrane zone. Indirect immunofluorescence (IIF) or enzyme-linked immunosorbent assays will confirm the deposit of autoantibodies specific for BP230 (also known as BPAG1) and/or BP180 (also known as BPAG2; collagen XVII $)^{[6,11]}$. Several cases have been reported with raised serum anti-BP180 associated with immunotherapyinduced $\mathrm{BP}$ as well ${ }^{[12]}$. Interestingly, in one case, it was demonstrated that immunotherapy-induced BP 
Table 1. Selected reported cases of immunotherapy-induced bullous pemphigoid

\begin{tabular}{|c|c|c|c|c|c|c|}
\hline $\begin{array}{l}\text { Case } \\
\text { number }\end{array}$ & Immunotherapy & $\begin{array}{l}\text { Primary } \\
\text { tumour }\end{array}$ & Clinical presentation & $\begin{array}{l}\text { Time to } \\
\text { develop BP } \\
\text { (weeks) }\end{array}$ & Treatment & Ref. \\
\hline 1 & Pembrolizumab & Melanoma & Cutaneous BP & 22 & Oral steroids & [27] \\
\hline 2 & Nivolumab & Tongue SCC & Oral and cutaneous BP & 8 & Topical/oral steroids & [9] \\
\hline 3 & Pembrolizumab & Melanoma & Cutaneous BP & 16 & Topical/oral steroids & [9] \\
\hline 4 & Nivolumab & Urothelial Ca. & Cutaneous BP & 18 & IV/oral steroids & {$[9]$} \\
\hline 5 & Nivolumab & NSCLC & Cutaneous BP & 6 & $\begin{array}{l}\text { Oral and topical steroids and } \\
\text { nicotinamide }\end{array}$ & [9] \\
\hline 6 & Nivolumab & Melanoma & Cutaneous BP & 3 & IV/oral steroids & [9] \\
\hline 7 & Pembrolizumab & Melanoma & $\begin{array}{l}\text { Severe BP } \\
\text { exacerbation }\end{array}$ & & Oral steroids & [28] \\
\hline 8 & Nivolumab & Lung cancer & Cutaneous BP & 6 & Oral steroids and omalizumab & [29] \\
\hline 9 & Pembrolizumab & Melanoma & Cutaneous BP & 84 & Topical and oral steroids & [30] \\
\hline 10 & $\begin{array}{l}\text { Ipilimumab then } \\
\text { nivolumab }\end{array}$ & Melanoma & Cutaneous BP & 24 & Topical and oral steroids & [23] \\
\hline 11 & $\begin{array}{l}\text { Durvalumab then } \\
\text { nivolumab }\end{array}$ & Melanoma & Cutaneous BP & 52 & Topical steroids & [23] \\
\hline 12 & Nivolumab & SCC of lung & Cutaneous BP & 18 & Oral and topical steroids & [23] \\
\hline 13 & $\begin{array}{l}\text { Pembrolizumab after } \\
\text { ipilimumab }\end{array}$ & Melanoma & Cutaneous BP & 32 & Oral and topical steroids & [31] \\
\hline 14 & Pembrolizumab & Melanoma & Oral and cutaneous BP & 78 & Topical steroid & [32] \\
\hline 15 & Pembrolizumab & Melanoma & Oral and cutaneous BP & 18 & Oral steroid and methotrexate & [32] \\
\hline 16 & Pembrolizumab & Melanoma & Recurrent BP & & Oral steroid & [32] \\
\hline 17 & $\begin{array}{l}\text { Pembrolizumab then } \\
\text { nivolumab }\end{array}$ & Melanoma & Localised BP & & Monitoring & [33] \\
\hline 18 & Nivolumab & Lung & Oral and cutaneous BP & 80 & IV Methylpred+ rituximab & [17] \\
\hline 19 & Pembrolizumab & Melanoma & Prolonged BP & 44 & Oral and topical steroids & [34] \\
\hline 20 & Nivolumab & Renal cell Ca. & Cutaneous BP & 12 & Oral and topical steroids & [35] \\
\hline 21 & Pembrolizumab & Melanoma & Cutaneous BP & 24 & Niacinamide & [36] \\
\hline 22 & Nivolumab & Melanoma & Cutaneous BP & 12 & Oral and topical steroids & [36] \\
\hline 23 & $\begin{array}{l}\text { Pembrolizumab and } \\
\text { ipilimumab }\end{array}$ & Melanoma & Cutaneous BP & 24 & IV and oral steroids and methotrexate & [37] \\
\hline 24 & Pembrolizumab & Melanoma & Cutaneous BP & 51 & Oral steroids & [38] \\
\hline 25 & Nivolumab & Skin SCC & Cutaneous BP & & Oral steroids and dapsone & [7] \\
\hline 26 & Nivolumab & Melanoma & Cutaneous BP & & Topical steroids & {$[7]$} \\
\hline 27 & Atezolizumab & Urothelial Ca. & Cutaneous BP & 22 & $\begin{array}{l}\text { Topical/oral steroids and omalizumab, } \\
\text { methotrexate }\end{array}$ & [12] \\
\hline 28 & Nivolumab & NSCLC & Cutaneous BP & & Topical/oral steroids & [12] \\
\hline 29 & Nivolumab & NSCLC & Cutaneous BP & & Topical/oral steroids and omalizumab & [12] \\
\hline 30 & $\begin{array}{l}\text { Nivolumab then } \\
\text { Pembrolizumab }\end{array}$ & NSCLC & Cutaneous BP & & $\begin{array}{l}\text { Topical and oral steroids and } \\
\text { nicotinamide }\end{array}$ & [12] \\
\hline 31 & $\begin{array}{l}\text { Pembrolizumab then } \\
\text { ipilimumab and nivolumab }\end{array}$ & Melanoma & Cutaneous BP & & $\begin{array}{l}\text { Topical and oral steroids and } \\
\text { nicotinamide }\end{array}$ & [12] \\
\hline 32 & Nivolumab & Renal cell Ca. & Cutaneous BP & & Oral steroids and nicotinamide & [12] \\
\hline 33 & Pembrolizumab & NSCLC & Cutaneous and oral BP & & Topical and oral steroids & [12] \\
\hline 34 & Pembrolizumab & Melanoma & MMP & 66 & Doxycycline only & [39] \\
\hline 35 & Pembrolizumab & Melanoma & Cutaneous BP & 12 & Topical and oral steroids & [14] \\
\hline 36 & $\begin{array}{l}\text { Ipilimumab then } \\
\text { pembrolizumab }\end{array}$ & Melanoma & Cutaneous BP & 29 & Topical and oral steroids & [14] \\
\hline 37 & Nivolumab & NSCLC & Cutaneous BP & 7 & $\begin{array}{l}\text { Topical and oral steroids and } \\
\text { niacinamide }\end{array}$ & [26] \\
\hline 38 & $\begin{array}{l}\text { Ipilimumab after } \\
\text { pembrolizumab }\end{array}$ & Melanoma & BP & & Oral and topical steroid & [40] \\
\hline 39 & Nivolumab & NSCLC & BP & & Oral steroids & [41] \\
\hline 40 & $\begin{array}{l}\text { Ipilimumab after } \\
\text { nivolumab }\end{array}$ & Melanoma & $\mathrm{BP}$ & 50 & Topical steroids & {$[42]$} \\
\hline 41 & Pembrolizumab & $\begin{array}{l}\text { Merkel cell } \\
\text { Ca. }\end{array}$ & MMP & 13 & Topical steroids & [43] \\
\hline 42 & Nivolumab & Melanoma & Oral and cutaneous BP & & Topical steroids & [44] \\
\hline 43 & Nivolumab & Renal cell Ca. & $\begin{array}{l}\text { BP on higher dose } \\
\text { immunotherapy }\end{array}$ & & Oral steroids & [18] \\
\hline
\end{tabular}




\begin{tabular}{|c|c|c|c|c|c|c|}
\hline 44 & Nivolumab & Melanoma & Cutaneous BP & & Topical/oral steroids and dapsone & [13] \\
\hline 45 & Nivolumab & Melanoma & MMP & & Topical steroids & [45] \\
\hline 46 & Pembrolizumab & Ovarian Ca. & Severe MMP & 3 & Topical and oral steroids & [46] \\
\hline 47 & Nivolumab & Lung & Oral and cutaneous BP & & Oral steroid & [8] \\
\hline 48 & Atezolizumab & Penile SCC & Photodistributed BP & & Oral steroids & [47] \\
\hline 49 & Atezolizumab & $\begin{array}{l}\text { Urothelial cell } \\
\text { Ca. }\end{array}$ & Cutaneous BP & 77 & $\begin{array}{l}\text { Topical steroids, doxycycline and } \\
\text { niacinamide }\end{array}$ & {$[15]$} \\
\hline 50 & Nivolumab & Renal cell Ca. & Cutaneous BP & 52 & IV and oral steroids & [48] \\
\hline 51 & $\begin{array}{l}\text { Durvalumab and } \\
\text { tremelimumab }\end{array}$ & NSCLC & $\mathrm{BP}$ & 42 & Oral steroids & [49] \\
\hline 52 & Cemiplimab & $\begin{array}{l}\text { Cutaneous } \\
\text { SCC }\end{array}$ & $\mathrm{BP}$ & & Oral steroids and rituximab & [50] \\
\hline
\end{tabular}

SCC: squamous cell cancer; Ca.: carcinoma; NSCLC: non-small cell lung cancer; MMP: mucous membrane pemphigoid; BP: bullous pemphigoid

may develop in the presence of anti-LAD-1 IgG antibodies alone but absence of anti-BP180 or anti-BP230 autoantibodies ${ }^{[13]}$.

Treatment regimens generally include steroids (oral or topical or combination), often in conjunction with discontinuation of immunotherapy. As steroids can potentially diminish immunomodulatory actions, topical steroids are first-line treatment for BP and are largely safe due to their limited systemic absorption. Meanwhile, oral nicotinamide and tetracycline (doxycycline or minocycline) have demonstrated a good effect in mild or moderate cases whilst completely avoiding systemic steroids ${ }^{[14,15]}$. The role of nicotinamide in treating BP is modulating inflammatory cytokines and acting as poly adenosine diphosphate ribose polymerase inhibitor ${ }^{[16]}$. However, severe cases have frequently required intravenous methylprednisolone $(1-2 \mathrm{mg} / \mathrm{kg})$. Refractory immunotherapy-induced BP shows response to rituximab or omalizumab ${ }^{[12,17]}$, which are started after immunotherapy discontinuation and lead to resolution of BP. Future studies are warranted to explore targeted immunosuppressant agents for severe steroid-refractory BP.

The question of resuming immunotherapy after resolution of BP remains under discussion. In the situations where immunotherapy is ineffective, discontinuation is clearly warranted. While in the context of a clinical response to immunotherapy, the discontinuation of immunotherapy is challenging, and the risks of continued treatment must be carefully weighed against its benefits. As such, the decision of resuming immunotherapy should be made as a part of multidisciplinary team and on an individual basis. In one case report BP developed after the patient was transitioned to a higher dose of nivolumab. Another case report showed improvement in BP after switching from nivolumab to pembrolizumab ${ }^{[18]}$. Consequently, immunotherapy should not be permanently discontinued without the trial of the previously tolerated dose or frequency or different immunotherapy.

Understanding the correlation between the incidence rate of skin irAEs and oncology benefit or immunotherapy resistance is critical for clinical practice. There is some evidence showing potential positive association between development of cutaneous irAEs and improved survival in patients on immunotherapy, particularly vitiligo ${ }^{[19,20]}$. In addition, a systematic review and meta-analysis suggested that the skin, gastrointestinal and endocrine irAEs might be positively associated with clinical benefit, while the pulmonary irAEs might be associated with immunotherapy resistance ${ }^{[21]}$. However, the development of severe BP in our case is not a marker of good response to immunotherapy, as the patient failed to respond to nivolumab despite the extensive, refractory, severe BP. Immunotherapy resistance can be classified as primary, such as in never-responders, or acquired, which emerges after a period of response ${ }^{[22]}$. Our patient had continuously slow disease progression in his metastatic left adrenal and left kidney mass since nivolumab, which could be primary immunotherapy resistance. However, we could not totally exclude the possibility of pseudo-progression, as his other metastatic diseases were largely stable. In a later phase, the 
extra use of steroids and cessation of nivolumab certainly further contributed to his disease progression. Consequently, understanding the correlation between skin irAEs and clinical outcome could provide valuable information in distinguishing between pseudo-progression and immunotherapy resistance, which will assist oncologists in the decision of resuming immunotherapy after the recovery from manageable skin irAEs.

The mechanism of immunotherapy induced BP is currently unclear. While BP is associated with both a humoral and a cellular response, it is widely believed that immunotherapy induced BP could be provoked by an autoantibody targeted to a sharedantigen and the dysfunction in T-regulatory cells, which is inhibited by immunotherapy ${ }^{[23]}$. The shared target antigen is located both at the dermoepidermal junction and on the surface of tumour cells, such as BP 180, whichcan be expressed on the surface of melanoma cells, nonsmall cell lung cancer cells and basement membrane skin cancer ${ }^{[2,25]}$. Meanwhile, dysregulation of PD-1/ PD-L1 and CTLA-4 signal pathway induced by immunotherapy can impair the balance within the immune system, resulting in the development of off-target effects and autoimmunity ${ }^{[26]}$. Further studies are required to determine the underlying mechanisms of immunotherapy induced BP.

\section{Conclusion}

Here, we report a rare case of severe, extensive and refractory nivolumab-induced BP in a patient with advanced renal cancer. With the widespread use of immunotherapy, it has become increasingly important to document cases of immunotherapy-induced BP to provide more information in diagnosing and treating these cutaneous adverse events. Moreover, the close collaboration between dermatologists and oncologists is essential to allow the patients with cutaneous irAEs to continue antitumor therapy, avoiding unnecessary discontinuation of immunotherapy.

\section{DECLARATIONS}

\section{Acknowledgments}

All authors would like to acknowledge Dr. Dalila Malek, Dr. Paul Gatt, Dr. Ravi Suchak and Dr. Marice Sudaerson (Southend Hospital) for support and advice.

\section{Authors' contributions}

Designed the study and wrote the manuscript: Wu X, Palvai S

Reviewed and approved the manuscript: Jalil A

\section{Availability of data and materials}

Not applicable.

\section{Financial support and sponsorship}

This study support by National Health Service Funding.

\section{Conflicts of interest}

All authors declared that there are no conflicts of interest.

\section{Ethical approval and consent to participate}

Written informed consent was obtained from the patient.

\section{Consent for publication}

Written informed consent was obtained from the patient for publication of this case report and any companying images. 


\section{Copyright}

(c) The Author(s) 2020.

\section{REFERENCES}

1. Schiavo AL, Ruocco E, Brancaccio G, Caccavale S, Ruocco V, Wolf R. Bullous pemphigoid: etiology, pathogenesis, and inducing factors: facts and controversies. Clin Dermatol 2013;31:391-9.

2. Amber KT, Panganiban CM, Korta D, Feraudy S, Kelly KM, Grando SA. A case report of bullous pemphigoid associated with a melanoma and review of the literature. Melanoma Res 2017;27:65-7.

3. Yatim A, Bohelay G, Grootenboer-Mignot S, et al. Paraneoplastic pemphigus revealed by anti-programmed Death-1 pembrolizumab therapy for cutaneous squamous cell carcinoma complicating hidradenitis suppurativa. Front Med (Lausanne) 2019;6:249.

4. Kridin K, Bergman R. Assessment of the prevalence of mucosal involvement in bullous pemphigoid. JAMA Dermatol 2019;155:166-71.

5. Ellis SR, Vierra AT, Millsop JW, Lacouture ME, Kiuru M. Dermatologic toxicities to immune checkpoint inhibitor therapy: A review of histopathologic features. J Am Acad Dermatol 2020;83:1130-43.

6. Buonavoglia A, Leone P, Dammacco R, et al. Pemphigus and mucous membrane pemphigoid: An update from diagnosis to therapy. Autoimmun Rev 2019;18:349-58.

7. Nahmias Z P, Merrill ED, Briscoe CC, et al. Development of bullous pemphigoid while receiving PD-1 checkpoint inhibitor nivolumab. SKIN J Cutane Med 2018:2:175-80.

8. Cuenca-Barrales C, Espadafor-López B, Martínez-López A, Cancela-Díez B, Ruiz-Villaverde R. Bullous pemphigoid in a patient treated with nivolumab. Dermatol Ther 2019;32:e13030.

9. Jour G, Glitza IC, Ellis RM, et al. Autoimmune dermatologic toxicities from immune checkpoint blockade with anti-PD-1 antibody therapy: a report on bullous skin eruptions. J Cutan Pathol 2016;43:688-96.

10. Amber KT, Valdebran M, Kridin K, Grando SA. The role of eosinophils in bullous pemphigoid: a developing model of eosinophil pathogenicity in mucocutaneous disease. Front Med (Lausanne) 2018;5:201.

11. Tampoia M, Giavarina D, Di Giorgio C, Bizzaro N. Diagnostic accuracy of enzyme-linked immunosorbent assays (ELISA) to detect antiskin autoantibodies in autoimmune blistering skin diseases: a systematic review and meta-analysis. Autoimmun Rev 2012;12:121-6.

12. Siegel J, Totonchy M, Damsky W, et al. Bullous disorders associated with anti-PD-1 and anti-PD-L1 therapy: A retrospective analysis evaluating the clinical and histopathologic features, frequency, and impact on cancer therapy. J Am Acad Dermatol 2018;79:1081-8.

13. Sadik CD, Langan EA, Grätz V, Zillikens D, Terheyden P. Checkpoint inhibition may trigger the rare variant of anti-LAD-1 IgG-positive, anti-BP180 NC16A IgG-negative bullous pemphigoid. Front Immunol 2019;10:1934.

14. Thomsen K, Diernaes J, Øllegaard TH, Spaun E, Vestergaard C. Bullous pemphigoid as an adverse reaction to pembrolizumab: two case reports. Case Rep Dermatol 2018;10:154-7.

15. Kosche C, Owen JL, Sadowsky LM, Choi JN. Bullous dermatoses secondary to anti-PD-L1 agents: a case report and review of the literature. Dermatol Online J 2019;25:6.

16. Fivenson DP, Breneman DL, Rosen GB, Hersh CS, Cardone S, Mutasim D. Nicotinamide and tetracycline therapy of bullous pemphigoid. Arch Dermatol 1994;130:753-8.

17. Sowerby L, Dewan AK, Granter S, Gandhi L, LeBoeuf NR. Rituximab treatment of nivolumab-induced bullous pemphigoid. JAMA Dermatol 2017;153:603-5.

18. Palla AR, Smith E, Doll D. Bullous pemphigoid associated with the 480-mg nivolumab dose in a patient with metastatic renal cell carcinoma. Immunotherapy 2019;11:1187-92.

19. Freeman-Keller M, Kim Y, Cronin H, Richards A, Gibney G, Weber JS. Nivolumab in resected and unresectable metastatic melanoma: characteristics of immune-related adverse events and association with outcomes. Clin Cancer Res 2016;22:886-94.

20. Sanlorenzo M, Vujic I, Daud A, et al. Pembrolizumab cutaneous adverse events and their association with disease progression. JAMA Dermatol 2015;151:1206-12.

21. Xing P, Zhang F, Wang G, et al. Incidence rates of immune-related adverse events and their correlation with response in advanced solid tumours treated with NIVO or NIVO+IPI: a systematic review and meta-analysis. J Immunother Cancer 2019;7:341.

22. Fares CM, Van Allen EM, Drake CG, Allison JP, Hu-Lieskovan S. Mechanisms of resistance to immune checkpoint blockade: why does checkpoint inhibitor immunotherapy not work for all patients? Am Soc Clin Oncol Educ Book 2019;39:147-64.

23. Naidoo J, Schindler K, Querfeld C, et al. Autoimmune bullous skin disorders with immune checkpoint inhibitors targeting PD-1 and PDL1. Cancer Immunol Res 2016;4:383-9.

24. Krenacs T, Kiszner G, Stelkovics E, et al. Collagen XVII is expressed in malignant but not in benign melanocytic tumors and it can mediate antibody induced melanoma apoptosis. Histochem Cell Biol 2012:138:653-7.

25. Papay J, Krenacs T, Moldvay J, et al. Immunophenotypic profiling of nonsmall cell lung cancer progression using the tissue microarray approach. Appl Immunohistochem Mol Morphol 2007:15:19-30.

26. Lopez AT, Geskin L. A case of nivolumab-induced bullous pemphigoid: Review of dermatologic toxicity associated with programmed cell death protein-1/programmed death ligand-1 inhibitors and recommendations for diagnosis and management. Oncologist 2018:23:1119-26.

27. Carlos G, Anforth R, Chou S, Clements A, Fernandez-Peñas P. A case of bullous pemphigoid in a patient with metastatic melanoma treated with pembrolizumab. Melanoma Res 2015;25:265-8.

28. Beck KM, Dong J, Geskin LJ, et al. Disease stabilization with pembrolizumab for metastatic acral melanoma in the setting of autoimmune 
bullous pemphigoid. J Immunother Cancer 2016;4:20.

29. Damsky W, Kole L, Tomayko MM. Development of bullous pemphigoid during nivolumab therapy. JAAD Case Rep 2016;2:442-4.

30. Mochel MC, Ming ME, Imadojemu S, et al. Cutaneous autoimmune effects in the setting of therapeutic immune checkpoint inhibition for metastatic melanoma. J Cutan Pathol 2016;43:787-91.

31. Lomax AJ, Ge L, Anand S, McNeil C, Lowe P. Bullous pemphigoid-like reaction in a patient with metastatic melanoma receiving pembrolizumab and previously treated with ipilimumab. Australas J Dermatol 2016:57:333-5.

32. Hwang SJ, Carlos G, Chou S, Wakade D, Carlino MS, Fernandez-Penas P. Bullous pemphigoid, an autoantibody-mediated disease, is a novel immune-related adverse event in patients treated with anti-programmed cell death 1 antibodies. Melanoma Res 2016;26:413-6.

33. Hirotsu K, Chiou AS, Chiang A, Kim J, Kwong BY, Pugliese S. Localized bullous pemphigoid in a melanoma patient with dual exposure to PD-1 checkpoint inhibition and radiation therapy. JAAD Case Rep 2017;3:404-6.

34. Parakh S, Nguyen R, Opie JM, Andrews MC. Late presentation of generalised bullous pemphigoid-like reaction in a patient treated with pembrolizumab for metastatic melanoma. Australas J Dermatol 2017:58:e109-12.

35. Kwon CW, Land AS, Smoller BR, Scott G, Beck LA, Mercurio MG. Bullous pemphigoid associated with nivolumab, a programmed cell death 1 protein inhibitor. J Eur Acad Dermatol Venereol 2017;31:e349-50.

36. Bandino JP, Perry DM, Clarke CE, Marchell RM, Elston DM. Two cases of anti-programmed cell death 1-associated bullous pemphigoidlike disease and eruptive keratoacanthomas featuring combined histopathology. J Eur Acad Dermatol Venereol 2017:31:e378-80.

37. Rofe O, Bar-Sela G, Keidar Z, Sezin T, Sadik CD, Bergman R. Severe bullous pemphigoid associated with pembrolizumab therapy for metastatic melanoma with complete regression. Clin Exp Dermatol 2017;42:309-12.

38. Wada N, Uchi H, Furue M. Bullous pemphigoid induced by pembrolizumab in a patient with advanced melanoma expressing collagen XVII. J Dermatol 2017;44:e240-1.

39. Zumelzu C, Alexandre M, Le Roux C, et al. Mucous membrane pemphigoid, bullous pemphigoid, and anti-programmed death-1/ programmed death-ligand 1: a case report of an elderly woman with mucous membrane pemphigoid developing after pembrolizumab therapy for metastatic melanoma and review of the literature. Front Med (Lausanne) 2018;5:268.

40. Hanley T, Papa S, Saha M. Bullous pemphigoid associated with ipilimumab therapy for advanced metastatic melanoma. JRSM Open 2018;9:2054270418793029.

41. Panariello L, Fattore D, Annunziata MC, Piantedosi F, Gilli M, Fabbrocini G. Bullous pemphigoid and nivolumab: dermatologic management to support and continue oncologic therapy. Eur J Cancer 2018;103:284-6.

42. Kuwatsuka Y, Iwanaga A, Kuwatsuka S, et al. Bullous pemphigoid induced by ipilimumab in a patient with metastatic malignant melanoma after unsuccessful treatment with nivolumab. J Dermatol 2018;45:e21-2.

43. Haug V, Behle V, Benoit S, et al. Pembrolizumab-associated mucous membrane pemphigoid in a patient with Merkel cell carcinoma. Br J Dermatol 2018;179:993-4.

44. Sturque J, Boralevi F, Fricain JC. Nivolumab-induced oral and cutaneous bullous pemphigoid: a case report. J Oral Med Oral Surg 2019;25:17.

45. Sibaud V, Vigarios E, Siegfried A, Bost C, Meyer N, Pages-Laurent C. Nivolumab-related mucous membrane pemphigoid. Eur J Cancer 2019;121:172-6.

46. Bezinelli LM, Eduardo FP, Migliorati CA, et al. A severe, refractory case of mucous membrane pemphigoid after treatment with pembrolizumab: brief communication. J Immunother 2019;42:359-62.

47. Leavitt E, Holland V. A case of atezolizumab-induced photodistributed bullous pemphigoid. Dermatol Ther 2019;32:e12924.

48. Anedda J, Atzori L, Rongioletti F, Pilloni L. Nivolumab bullous pemphigoid: case description and literature review. J Clin Exp Pathol 2019;9:364.

49. Fontecilla NM, Khanna T, Bayan CAY, Antonov NA, Geskin LJ. Bullous pemphigoid associated with a new combination checkpoint inhibitor immunotherapy. J Drugs Dermatol 2019;18:103-4.

50. Virgen CA, Nguyen TA, Di Raimondo C, et al. Bullous pemphigoid associated with cemiplimab therapy in a patient with locally advanced cutaneous squamous cell carcinoma. JAAD Case Rep 2020;6:195-7. 